
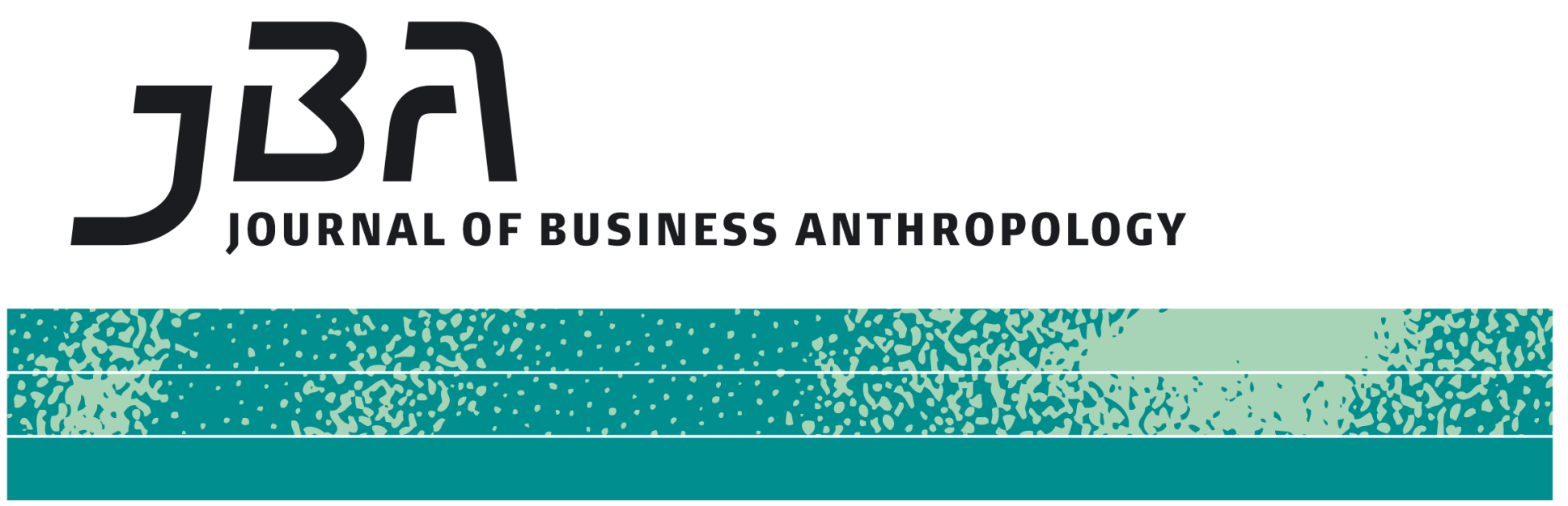

\title{
Forms of Expectations about Future Returns*
}

\author{
Kyung-Nan Koh
}

In recent years, there has been a noticeable trend in US institutional philanthropy and charity with donors and recipients both publicly pronouncing how giving and receiving are acts of reproducing social good. In corporate giving, more companies are now shifting away from what is called "traditional" philanthropy - that is, the handling of cash or in-kind donations on an ad hoc basis-to a more "responsible," "focused," and even "strategic" giving. In actual sites of philanthropy and charity, it is

Page 1 of 4

JBA 6(2): 235-238

Autumn 2017

(C) The Author(s) 2017 ISSN 2245-4217

www.cbs.dk/jba often discussed how limited resources can be "effectively" if not "strategically" given to "maximize" the effects and for funding cycles to continue (i.e., "reproduction"). Like Pay-What-You-Want (PWYW) pricing however, there is not yet agreement as to whether or not focused giving or strategic philanthropy leads to profit (Greene 1990, McWilliams and Siegel 2000, Porter and Kramer 2006).

Meanwhile, with increased attention to what happens after gifts are given, there are also increasing considerations as to whether or not there will be some form of return in actual moments of decision making. In fact, the question of reciprocity often shapes the very design of corporate giving programs as well as the decisions as to how much and to whom to give. In carrying out ethnographic research on corporate social responsibility (CSR), I observed several major US corporations that were

\footnotetext{
*Comment on Egbert, Henrik, "Pay-What-You-Want Pricing," in this issue.
} 
clients of a CSR consulting company adopt the practice of employee engagement in community relations activities and philanthropy. A corporation called Tobacco USA (a pseudonym) operates an employee fund where employees contribute to and make decisions about giving. From the perspective of Tobacco USA, the corporation, the return on having this program was simply rationalized as the favorable evaluations from employees to the corporation (see also Grant, Dutton, and Rosso (2008)); it was expected that positive employee experiences will provide future PR opportunities to depict real employees and not the cigarette maker as the giver.

Reciprocity was differently imagined in the case of employees who struggled with the difficult question of what, who, and how much to give. In a three-day long annual "Grantmaking Meeting Days," elected representatives representing various departments, shifts, and facilities gathered as a committee. The committee's task was to review and rank over 150 applications and decide how to distribute cash contributions to potential 501(c)3 nonprofit recipients. In discussions, the committee agreed that proposals are "weak" when the service area of the nonprofit is unoccupied by a significant number of corporate employees. Among the applications categorized as weak however, some nonprofits were still given full funding after committee members' reports that "[signs of] Tobacco USA Employee Fund is [displayed] all over the place." On the other hand, interestingly, they were also keen on the issue of organizational stability of possible receivers: In several cases, revelations of internal politics or impending staff changes within nonprofits led to reductions in the amount of giving. Meanwhile, in reviewing an application that asked for support of staff's salary, a remark that "I can't go back to the factory and say I spent $\$ 70,000$ for salary, for a case of buying hours" resulted in a denial of funding.

What can be seen from these examples that exemplify the most salient concerns expressed is that in this form of participative giving, the choices depended on and were justified against the entire corporate employees' expectation that the 'generosity' of giving continues to circulate via discourses and signs, and hence the employee-run corporate philanthropy continues on into the future. In their decisions, the committee (i.e., employee representatives) upheld objectivity and fairness as ideologically important. But so was to investigate whether the decisions will not "kill the Fund" by inviting, to quote and for example, possible fellow employee's criticism such as "I'm not going to give you money cause you didn't fund my area"; or by giving to nonprofits whose future cannot be more certainly imagined and hence risk the chance of seizing reciprocal returns (i.e., again, in various forms of circulation of signs of generosity that can reassure actual givers that the money is well given). Thus, the committee members wished to avoid giving to receivers who show signs that point to possible failures in the maintenance of 
employees' expectation about the continuation of the fund.

In her study on Indian philanthropy, Bornstein (2009) suggests that we try to attend to the "impulse" of giving rather than the effects in order to better grasp the processes and tensions involved in giving. In reference to Max Weber's ideas on charity, she argues that the emphases on responsibility and accountability in modern philanthropy work to regulate the more spontaneous, disinterested, or traditional forms of giving, resulting in philanthropy becoming "instrumentally rational" $(2009,642)$. To a certain extent, Bornstein's observation resonates with the case of philanthropy briefly discussed here where talks of responsibility and accountability - not only to receivers but also giversdiscursively work to rationalize giving decisions. What Tobacco USA's case further implies however is that such rationalization of philanthropy aimed at ensuring reciprocity is, in fact, an effort to maintain the expectation that gift exchange continues to reproduce future "good" (Himmelstein 1997).

In business anthropology, Mauss's Gift has been useful to explain consumer experiences (see Joy and Li's (2012) review of "consumer culture theory") as well as to develop models of systems of consumer exchange (Sherry 1983, Giesler 2006). In this welcoming paper, Egbert suggests that long-term PWYW pricing strategies and economics can also benefit from the application of the Gift. As I have here tried to suggest, it may be useful to simultaneously consider how reciprocity is an expectation held by rationalizing social actors, which in Mauss is ritualistically and in contemporary market transactions is "metaculturally" (Urban 2001) maintained and achieved.

\section{References}

Bornstein, Erica. 2009. "The Impulse of Philanthropy." Cultural Anthropology 24 (2): 622-651. https://doi.org/10.1111/j.15481360.2009.01042.x

Giesler, Markus. 2006. "Consumer Gift Systems." Journal of Consumer Research 33 (2): 283-290. https://doi.org/10.1086/506309

Grant, Adam M., Jane E. Dutton, and Brent D. Rosso. 2008. "Giving Commitment: Employee Support Programs and the Prosocial Sensemaking Process." Academy of Management Journal 51 (5): 898-918. https://doi.org/10.5465/amj.2008.34789652

Greene, Shelby D. 1990. "Corporate Philanthropy and the Business Benefit: The Need for Clarity." Golden Gate University Law Review 20: 239260 . 
Himmelstein, Jerome L. 1997. Looking Good and Doing Good: Corporate Philanthropy and Corporate Power. Bloomington: Indiana University Press.

Joy, Annamma , and Eric P. H. Li. 2012. "Studying Consumption Behaviour through Multiple Lenses: An Overview of Consumer Culture Theory." Journal of Business Anthropology 1 (1): 141-173.

McWilliams, Abagail, and Donald Siegel. 2000. "Corporate Social Responsibility and Financial Performance: Correlation or Misspecification?" Strategic Management Journal 21 (5): 603-609. https://doi.org/10.1002/(sici)1097-0266(200005)21:5<603::aidsmj101>3.3.co;2-v

Porter, Michael E., and Mark R. Kramer. 2006. "Strategy and Society: The Link between Competitive Advantage and Corporate Social Responsibility." Harvard Business Review (December): 6-20. https://doi.org/10.1108/sd.2007.05623ead.006

Sherry, John F., Jr. 1983. "Gift Giving in Anthropological Perspective." Journal of Consumer Research 10 (2): 157-168.

https://doi.org/10.1086/208956

Urban, Greg. 2001. Metaculture: How Culture Moves through the World. Minneapolis: University of Minnesota Press.

\section{Acknowledgements}

This work was supported by the National Research Foundation of Korea (NRF) Grant funded by the Korean Government (MEST) (NRF-2010-361A00013).

\footnotetext{
Kyung-Nan Koh is Assistant Professor of Anthropology at the Semiosis Research Center of Hankuk University of Foreign Studies (Seoul, South Korea). She received her PhD in Anthropology from the University of Pennsylvania in 2010. She has conducted research on the cultural and semiotic processes of dissemination, translation, branding, and performance of corporate social responsibility in the U.S.A., and is currently interested in the gendered corporate languages in South Korea. Her publications include "How Brands Don't Do Things" (Semiotica), "Translating 'Sustainability' in Hawai'i" (The Asia-Pacific Journal of Anthropology, Winner of Nadel Essay Prize), "Semiotic Corporation" (a Signs and Society Supplement Issue, co-edited with Greg Urban), and the Korean translation of The Pragmatic Semiotics of Cultures by Richard J. Parmentier. She is co-founder and Managing Editor of Signs and Society (University of Chicago Press).
} 